Discussion Paper No. 05-70

\title{
Does it Pay to Watch Central Bankers' Lips? The Information Content of ECB Wording
}

Friedrich Heinemann and Katrin Ullrich

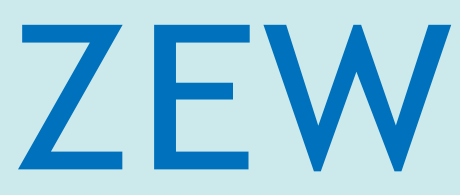

Zentrum für Europäische Wirtschaftsforschung $\mathrm{GmbH}$ Centre for European Economic Research 
Discussion Paper No. 05-70

\section{Does it Pay to \\ Watch Central Bankers' Lips? The Information Content of ECB Wording}

Friedrich Heinemann and Katrin Ullrich

Download this ZEW Discussion Paper from our ftp server:

ftp://ftp.zew.de/pub/zew-docs/dp/dp0570.pdf

Die Discussion Papers dienen einer möglichst schnellen Verbreitung von neueren Forschungsarbeiten des ZEW. Die Beiträge liegen in alleiniger Verantwortung der Autoren und stellen nicht notwendigerweise die Meinung des ZEW dar.

Discussion Papers are intended to make results of ZEW research promptly available to other economists in order to encourage discussion and suggestions for revisions. The authors are solely responsible for the contents which do not necessarily represent the opinion of the ZEW. 


\section{Non-Technical Summary}

The public at large and especially central bank watchers, financial media and market participants pay considerable attention to central bankers' statements. Every word is evaluated with regard to possible signals about future monetary policy decisions. In the academic literature, analysis of communication is a growing field of research but quantification of rhetoric signals is difficult and more or less prone to subjective judgement. In our analysis, we try to assess the informational content of the monthly press conferences for future interest rate decisions of the ECB. We suggest a more objective construction of a wording indicator. For this purpose our index construction is based on an algorithm which can be understood as representing a learning process of ECB observers. In this algorithm the relevant code words, their sign and their weight are chosen on the basis of statistical criteria exploiting different frequencies of code words' appearance in neutral, expansionary or restrictive monetary policy phases.

Our analysis is solely related to the link between communication and the likely future monetary path. To investigate this relation, we deal with two distinct but closely related questions: First, is central bank watching based on a counting of code words alone an efficient information technique in the sense that this strategy does not perform substantially worse than other more subtle techniques? And second, do wording indicators in addition to economic data offer valuable information for the explanation of central bank rates?

In the empirical analysis, we employ a monetary reaction function extended by the wording indicator. Our results indicate that the decoding of rhetoric signals is useful because wording includes information helpful to improve the explanation of interest rate decision based on standard explanatory models. This result is confirmed on the basis of out of sample analysis where the period on which the wording indicator's choice of weights is based is not included in testing this indicator's significance. We conclude that ECB wording has an information content which cannot fully be replicated by Taylor type regressions. But simple decoding of central bankers' messages cannot substitute a more thorough analysis of economic data. Our findings indicate that judgements based solely on analysing central bankers' speeches are inferior to more refined approaches based on models and economic data. 


\title{
Does it Pay to Watch Central Bankers' Lips? The Information Content of ECB Wording
}

\author{
Friedrich Heinemann and Katrin Ullrich \\ Centre for European Economic Research (ZEW), Mannheim \\ Revised version September 2005
}

\begin{abstract}
In this analysis, the informational content of central bank rhetoric is assessed based on the experience with the ECB since 1999. Among the ECB's communication channels we focus on the monthly press conferences. Based on a counting of certain signal words we construct a wording indicator reflecting the "hawkishness" of monetary rhetorics. For the construction, we develop an objective algorithm representing a learning process of ECB observers. We then integrate this indicator into a standard Taylor type ordered probit model for the explanation of the interest rate. We show that the wording indicator can improve the model's fit when added to the standard explanatory variables. However, a model based solely on this indicator performs worse than the baseline. The results are confirmed by out of sample analysis where the determination of the wording indicators' weights is based on the early ECB period which, subsequently, is excluded from the tests. Our conclusion is that linguistic analysis can improve but not substitute more rigorous forecasting techniques based on hard economic data.
\end{abstract}

Acknowledgment: We are grateful for helpful suggestions from Carlo Rosa, Michael Ehrmann, Lucian Orlowski and the participants of the National Bank of Poland Conference "Central Bank Transpareny and Communication: Implications for Monetary Policy" in Warsaw in June 2005. We thank Gunnar Lang for able research assistance.

\section{JEL-Classification: E 52, E 43}

Keywords: Taylor rule, wording, central bank communication

Friedrich Heinemann

P.O. Box 103443

68034 Mannheim

Germany

Phone: $\quad+496211235149$

Fax: $\quad+496211235223$

E-mail: heinemann@zew.de
Katrin Ullrich

P.O. Box 103443

68034 Mannheim

Germany

Phone: $\quad+496211235145$

Fax: $\quad$ +496211235223

E-mail: ullrich@zew.de 


\section{Introduction}

Central bank watchers, financial media and market participants pay considerable attention to central bankers' statements. Even slight nuances of wording are being scrutinised with regard to possible signals about future monetary policy decisions. In the financial press, lists of code words are reported together with their alleged monetary policy interpretation (e.g., without author (2003)). Examples exist where the linguistic analysis of central bank publications is used to construct a measure of rhetoric "hawkishness" which then serves as an input for assessing the monetary policy outlook (Mayer, 2004).

Practitioners' attention to central bank wordings stands in contrast to academic approaches to explain and forecast central bank decisions. In the literature, approaches dominate which are based on objectively quantifiable economic data, e.g. in the context of specifying Taylor type rules. This self-restriction is related to technical difficulties of quantifying rhetoric signals. A further and more serious reason, however, might be the assumption that financial market actors form expectations on the basis of the full set of available economic data and that central bank rhetoric does not include any informational value added. If the latter assumption were true the watching of central bankers' lips would have to be regarded as a forecasting technique being inferior to more technical approaches.

In our analysis, we try to assess the informational content of central bank rhetoric for future central bank rates based on the experience with the ECB since 1999. Among the ECB's communication channels we focus on the monthly press conferences.

In essence, we deal with two distinct but closely related questions: First, is central bank watching based solely on a counting of code words an efficient information technique in the sense that this strategy does not perform substantially worse than other more subtle 
techniques? And second, do wording indicators in addition to hard economic data offer valuable information for the explanation of central bank rates?

Our results tend to negate the first question and to answer the second question in the affirmative. Although the simple decoding of central bankers' messages cannot substitute a thorough analysis of economic data, our findings clearly support the rationality of central bank watchers' attention for linguistic specificities. Obviously, ECB wording has an information content which cannot fully be replicated by Taylor type regressions. Thus, it is rational information collecting when market actors pay attention to the subtleties of wording. In the academic literature, there exist only a few studies testing for certain informational contents of ECB wording which are closely related to our work (Rosa and Verga, 2005; Gerlach, 2004). A common characteristic of these rare attempts, however, is a subjective construction of wording indices. This means that the authors' own judgement guides the interpretation of certain formulation of ECB representatives and the sign and weights of code words in the overall indicator. We follow a different approach by suggesting a more objective construction of a wording indicator. For this purpose our index construction is based on an algorithm which can be understood as representing a learning process of ECB observers. In this algorithm the relevant code words, their sign and their weight are chosen on the basis of statistical criteria exploiting different frequencies of code words' appearance in neutral, expansionary or restrictive monetary policy phases.

This study is also related to other strands of research dealing with monetary predictability and the impact of central bank communication on financial markets.

For example, the ECB has been surveyed regarding its transparency and communication policy. Ross (2002) examines the predictability of ECB policy decisions using the persistence of interest rate changes via the smoothing parameter included in the Taylor rule, federal funds futures to predict changes in the monetary policy of the Fed and the short-term end of a forward curve calculated by the Bank of England and the EONIA for the ECB. He concludes 
that the predictability of the ECB is lower than that of the other two banks. On the other hand, Gaspar et al. (2001) come to the conclusion, that announcements of monetary policy decisions do not change the stochastic behaviour of the EONIA, which indicates that market participants have anticipated interest rate decisions.

The bias announcement which had been practiced by the Fed is, of course, a very direct and explicit monetary signal which as such does not exist in the ECB's context. This bias announcement includes significant information, which may help to predict the Federal Reserve's interest rate decisions (Conley, Dupor and Mirzoev 2004).

By concentrating on the press conference given to explain the interest rate decisions, we can ignore the finding of Jansen and De Haan (2004) that statements of central bankers on interest rates, inflation and economic growth have been different and even contradictory with respect to central banker from the ECB and the national central banks of the euro area. However, over time, the interest rate statements have become less contradictory.

A further focus of related literature is the impact of announcements and communication on financial market variables like capital market rates or exchange rates. Andersson, Dillén and Selling (2001) find, that the long-term interest rates are influenced by signals from speeches of central bankers from the Swedish central bank. This influence might even be larger than unexpected changes in the official rate. Guthrie and Wright (2000) find a clear announcement effect for interest rates along all maturities in the case of New Zealand. Studies related to the impact of communication on exchange rates are Fratzscher (2004) and Jansen/de Haan (2004).

Faust, Swanson und Wright (2004) find little evidence that monetary policy surprises from the Federal Reserve convey superior information that may be used to improve the private sector forecast of statistical releases. This is a finding interesting in our context since central bank private information could be one of the reasons for the informative value added of central bankers' statements. 
Summing up, the existing studies are of a more indirect nature compared to ours'. In many of these analyses, central bank announcements are seen to change market participants' expectations of the future monetary stance with immediate consequences for the pricing of certain financial assets. Our analysis is more focused and solely related to the first step of the logical chain, the link between communication and the likely future monetary path.

In the next section we give a brief exposition of our analytical strategy, followed by the construction of a wording index in section 3. Section 4 presents our central econometric test. Section 5 summarizes our findings and concludes.

\section{Analytical approach}

There are basically two different potential explanations for the markets' attention to central bank wording. Our empirical strategy is designed to differentiate between both.

First, information strategies based on the exegesis of central bank statements may be a costefficient alternative to more rigorous approaches based on implicit or explicit models and a collection of all relevant data. The Fed's former bias announcement illustrates this interpretation: If a central bank credibly states what it intends to do in the coming months, market participants could try to economize on forecasting efforts and - in the extreme - even stop devoting any resource to this activity apart from following official statements.

The second explanation points towards a less demanding function of rhetoric signals. Even if these signals may not be able to replace more thorough forecasting techniques they might be useful to improve these forecasts. This should be the case if one of the following two conditions is fulfilled: The central bank has private information on data being relevant for future monetary decision or market actors are uncertain about the correct decision model. As cited above, for the Fed the study of Faust, Swanson und Wright (2004) does not support the existence of substantial private information but the situation could be different for Europe. 
Furthermore, the relative short history of the ECB is a strong argument in favour of model uncertainty on the side of ECB watchers. For example, it may be unclear how (common knowledge) data on heterogeneous developments in the Euro zone affect the decision making in the Council (Heinemann and Hüfner, 2004). In these cases, wording signals can be an input to forecasting models being able to improve the model's fit.

Our empirical strategy, consecutively, tests for both potential functions. I.e. we test the following two distinct hypotheses:

Hypothesis 1:

Central bank watching and de-coding of wording is a substitute for thorough model analyses.

Hypothesis 2:

Wording includes information helpful to improve the explanation of interest rate decisions based on standard explanatory models.

In order to test hypothesis 1, we check the fit of a model explaining ECB rates solely on the basis of their own history and our wording indicator. Hypothesis 2 is tested by augmenting a standard Taylor equation with our wording indicator as additional regressor.

Before proceeding with this strategy, in the following section, we describe the construction of our wording index.

\section{Learning and the construction of a wording index}

Our attempt to decode and quantify the ECB's rhetoric messages starts by identifying possible signal words and further characteristics of communication policies. In order to base the analysis on a regular stream of communication signals we focus on ECB press conferences 
which offer a monthly frequency and which are carefully analysed by ECB watchers. On the basis of these potential code words our construction of the wording index that can be interpreted as describing a simple learning process of ECB watchers. The learning process assumes that observers of monetary policy look for significant differences in the frequencies of potential code words in different monetary policy phases. Monetary phases are classified depending on the subsequent interest rate policies, i.e. whether the month of observation is preceding a two months period with rate cuts, rate increases and unchanged rates, respectively. Observing significant differences in frequencies among these monetary phases, subsequently allows ECB observers to draw conclusions from wording about future monetary decisions.

A convincing test for the usefulness of any such learning process must rely on out of sample analysis. This means that the period of learning on the one hand and the period of testing the learning results' usefulness on the other hand need to be non-overlapping. Therefore, we construct two variants of our wording indicators based on different periods in order to prepare for out of sample testing in the next section.

Starting point is the identification of potential code words. Here we make use of lists circulating among practitioners (Without author, 2003) and as they are used in the related academic studies (Rosa and Verga, 2005). Table A in the appendix lists the code words included in our subsequent algorithm. We also include into our list a variable measuring the length of the President's introductory statement. This communication characteristic could play a role assuming that preparing the ground for a change in interest rates might need more words compared to a situation of continuing passivity.

In order to test these words' informational content we count their use in the introductory statements in each monthly ECB press conferences. In those months where no press conference took place we take the editorials of the monthly ECB reports as substitute which are very similar in contents, length and terminology to the press conferences' initial 
statements. In order to safeguard a high degree of objectivity we abstain from taking into account the context of the terms' use apart from unequivocal negations. For example, we do treat a statement like "there is no risk to price stability" as if "risk to price stability" was not mentioned. We then group observations into periods of neutrality, tightening and easing bias. Our grouping criterion is the observed interest policy of the two months following the press conference.

Figure 1 shows frequency means of code words depending on the character of the monetary policy stance judged on the basis of the interest rate decision in the following two months. Press conferences preceding interest rate increases are characterized by a more frequent use of "vigilant", "risks to price stability/inflation", "second round effects" or "favourable outlook for growth". Apart from that, statements are longer. During more passive stages the ECB president more frequently uses words like "appropriate", "in line", "consistent with price stability" or balanced. Code word used more frequently in phases preceding interest rate cuts are "to monitor", "downside risks to growth" or "economic slowdown". However, not all of these differences are significant. Tables 1 and 2 summarise the results of ANOVA tests for the equality of means in the frequency of these words' frequencies for the period January 1999 - October 2003 which is the period of Wim Duisenberg being ECB president and for a two year sub-section of the Duisenberg era, respectively. 
Figure 1: Frequency means of code words in press conferences depending on monetary policy phase (era Duisenberg 1999:01-2003:10)

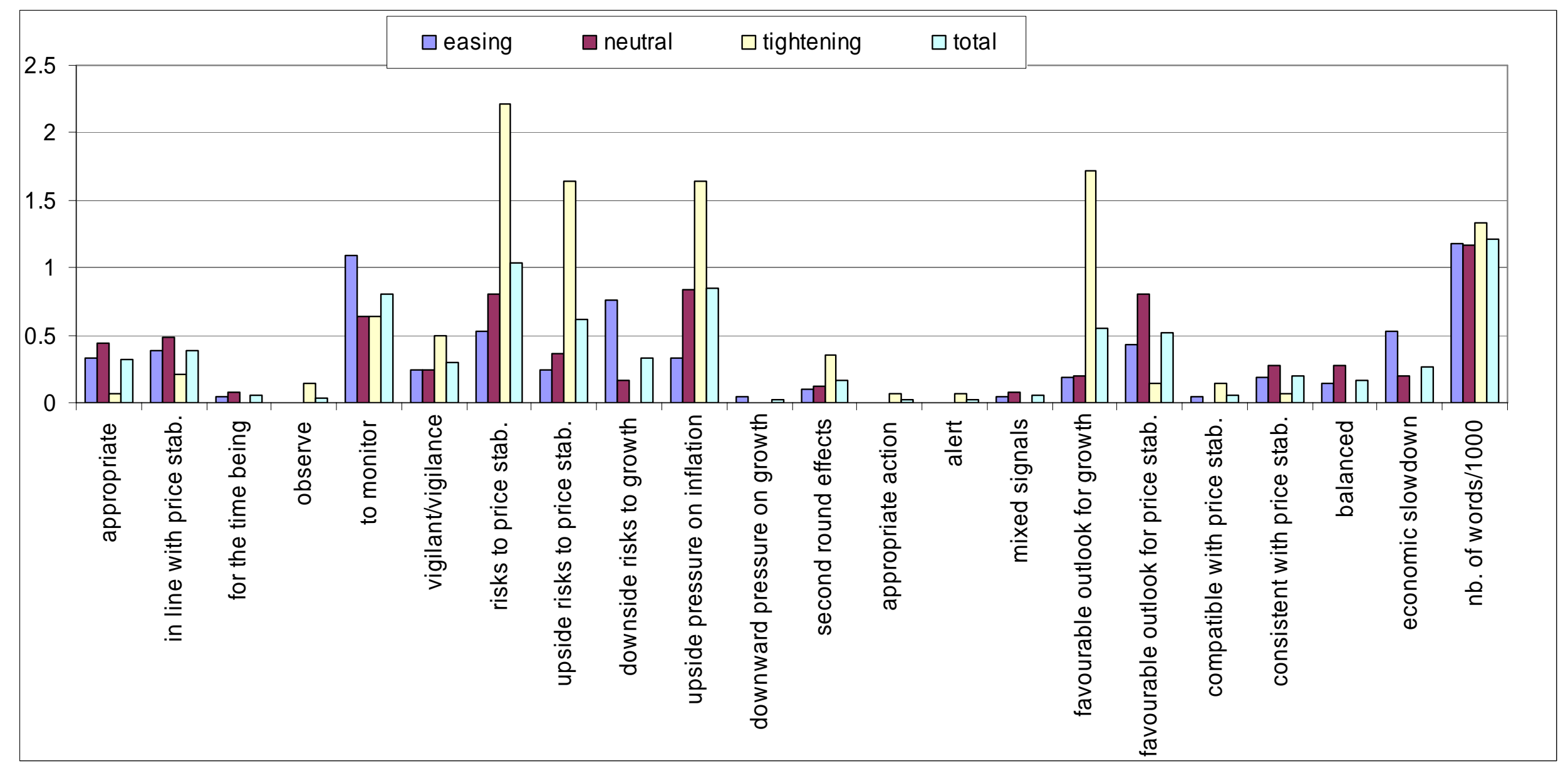


Table 1: Analysis of variance - Duisenberg era

\begin{tabular}{|l|r|r|r|}
\hline & F-statistic & significance & $\eta^{2}$ \\
\hline appropriate & 2.54 & 0.087 & 0.082 \\
in line with price stability & 1.03 & 0.364 & 0.035 \\
for the time being & 0.59 & 0.559 & 0.020 \\
observe & 3.64 & 0.032 & 0.113 \\
to monitor & 1.97 & 0.149 & 0.065 \\
vigilant/vigilance & 1.75 & 0.182 & 0.058 \\
risks to price stability & 12.19 & 0.000 & 0.300 \\
upsiderisks to price stability & 13.56 & 0.000 & 0.322 \\
downside risks to growth & 9.16 & 0.000 & 0.243 \\
upside pressure on inflation & 6.71 & 0.002 & 0.190 \\
downward pressure on growth & 0.93 & 0.402 & 0.031 \\
second round effects & 2.49 & 0.092 & 0.080 \\
appropriate action & 1.68 & 0.195 & 0.056 \\
alert & 1.68 & 0.195 & 0.056 \\
mixed signals & 0.59 & 0.559 & 0.020 \\
favourable outlook for growth & 29.28 & 0.000 & 0.507 \\
favourable outlook for price & & & \\
stability & 3.19 & 0.049 & 0.101 \\
compatibe with price stability & 1.96 & 0.150 & 0.064 \\
consistent with price stability & 0.85 & 0.433 & 0.029 \\
balanced & 1.51 & 0.229 & 0.050 \\
economic slowdown & 3.35 & 0.042 & 0.105 \\
number of words & 2.04 & 0.139 & 0.067 \\
\hline
\end{tabular}

January 1999-October 2003, 60 observations (two press conferences in March 2000 and June 2001). $\eta^{2}$ is computed as between-groups sum of squares divided by total sum of squares.

On the basis of a $10 \%$ significance level a number of potential signal words do not show significant differences in mean frequencies. Those code words are excluded from the following calculations. Exclusions differ between the total Duisenberg period and the subperiod. The differences in the mean length of the statements miss significance and are dropped as well in both period definitions. 
Table 2: Analysis of variance - restricted database 1999-2000

\begin{tabular}{|l|r|r|r|}
\hline & F-statistic & significance & $\eta^{2}$ \\
\hline appropriate & 0.37 & 0.693 & 0.033 \\
in line with price stability & 3.15 & 0.063 & 0.223 \\
for the time being & - & - & - \\
observe & 0.81 & 0.459 & 0.068 \\
to monitor & 3.42 & 0.051 & 0.237 \\
vigilant/vigilance & 4.84 & 0.018 & 0.306 \\
risks to price stability & 6.16 & 0.008 & 0.359 \\
upsiderisks to price stability & 5.47 & 0.012 & 0.332 \\
downside risks to growth & 58.08 & 0.000 & 0.841 \\
upside pressure on inflation & 2.02 & 0.157 & 0.155 \\
downward pressure on growth & 4.84 & 0.018 & 0.306 \\
second round effects & 1.27 & 0.302 & 0.103 \\
appropriate action & 0.37 & 0.693 & 0.033 \\
alert & 0.37 & 0.693 & 0.033 \\
mixed signals & 4.84 & 0.018 & 0.306 \\
favourable outlook for growth & 6.87 & 0.005 & 0.385 \\
favourable outlook for price & & & \\
stability & 2.64 & 0.093 & 0.194 \\
compatibe with price stability & 0.81 & 0.459 & 0.068 \\
consistent with price stability & 0.37 & 0.693 & 0.033 \\
balanced & 2.13 & 0.143 & 0.162 \\
economic slowdown & 9.51 & 0.001 & 0.464 \\
number of words & 0.00 & 0.996 & 0.000 \\
\hline
\end{tabular}

January 1999-December 2000, 25 observations (two press conferences in March 2000). No use of "for the time being" in this period.

Since the ANOVA assesses differences in mean across all groups it does not give a direct insight on pair-wise differences. For this purpose, for the words with significant F-tests we present least significant distance tests (Table 3 and Table 4) indicating which of the pair-wise differences in means show significance. 
Table 3: Pair-wise differences in means (least significance distance) - Duisenberg era

\begin{tabular}{|c|c|c|c|}
\hline & & $\begin{array}{l}\text { difference } \\
\text { in mean }\end{array}$ & significance \\
\hline \multirow[t]{3}{*}{ appropriate } & neutral vs. easing & 0.11 & 0.466 \\
\hline & tightening vs. easing & -0.26 & 0.128 \\
\hline & tightening vs. neutral** & -0.37 & 0.028 \\
\hline \multirow[t]{3}{*}{ observe } & neutral vs. easing & 0.00 & 1.000 \\
\hline & tightening vs. easing** & 0.14 & 0.020 \\
\hline & tightening vs. neutral ${ }^{\star \star}$ & 0.14 & 0.017 \\
\hline \multirow[t]{3}{*}{ risks to price stability } & neutral vs. easing & 0.28 & 0.373 \\
\hline & tightening vs. easing ${ }^{\star \star \star}$ & 1.69 & 0.000 \\
\hline & tightening vs. neutral ${ }^{\star \star \star}$ & 1.41 & 0.000 \\
\hline \multirow{3}{*}{$\begin{array}{l}\text { upside risks to price } \\
\text { stability }\end{array}$} & & & \\
\hline & 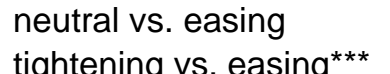 & $\begin{array}{l}0.12 \\
1.40\end{array}$ & $\begin{array}{l}0.628 \\
0.000\end{array}$ \\
\hline & tightening vs. neutral ${ }^{\star \star \star}$ & 1.28 & 0.000 \\
\hline \multirow[t]{3}{*}{ downside risks to growth } & 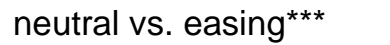 & -0.60 & 0.001 \\
\hline & tightening vs. easing & -0.76 & 0.000 \\
\hline & tightening vs. neutral & -0.16 & 0.412 \\
\hline \multirow[t]{3}{*}{$\begin{array}{l}\text { upside pressure on } \\
\text { inflation }\end{array}$} & neutral vs. easing & 0.51 & 0.104 \\
\hline & tightening vs. easing & 1.31 & 0.001 \\
\hline & tightening vs. neutral** & 0.80 & 0.024 \\
\hline \multirow[t]{3}{*}{ second round effects } & neutral vs. easing & 0.02 & 0.820 \\
\hline & tightening vs. easing** & 0.26 & 0.043 \\
\hline & tightening vs. neutral ${ }^{*}$ & 0.24 & 0.058 \\
\hline \multirow{3}{*}{$\begin{array}{l}\text { favourable outlook for } \\
\text { growth }\end{array}$} & neutral vs easina & 0.01 & 0.961 \\
\hline & tightening vs. easing & 1.52 & 0.000 \\
\hline & tightening vs. neutral ${ }^{\star \star \star}$ & 1.51 & 0.000 \\
\hline \multirow[t]{3}{*}{$\begin{array}{l}\text { favourable outlook for } \\
\text { price stability }\end{array}$} & neutral vs. easing & 0.37 & 0.124 \\
\hline & tightening vs. easing & -0.29 & 0.307 \\
\hline & tightening vs. neutral** & -0.66 & 0.017 \\
\hline \multirow[t]{3}{*}{ economic slowdown } & neutral vs. easing* & -0.32 & 0.078 \\
\hline & tightening vs. easing ${ }^{\star \star}$ & -0.52 & 0.016 \\
\hline & tightening vs. neutral & -0.20 & 0.330 \\
\hline
\end{tabular}

$* / * * / * * *$ : significance at $10 \% / 5 \% / 1 \%$ 
Table 4: Pair-wise differences in means (least significance distance) - restricted database

1999-2000

\begin{tabular}{|c|c|c|c|}
\hline & & $\begin{array}{l}\text { difference } \\
\text { in mean }\end{array}$ & significance \\
\hline in line with price stability & $\begin{array}{l}\text { neutral vs. easing } \\
\text { tightening vs. easing } \\
\text { tightening vs. neutral** }\end{array}$ & $\begin{array}{r}0.54 \\
-0.12 \\
-0.66\end{array}$ & $\begin{array}{l}0.195 \\
0.758 \\
0.021\end{array}$ \\
\hline to monitor & $\begin{array}{l}\text { neutral vs. easing }{ }^{\star *} \\
\text { tightening vs. easing } \\
\text { tightening vs. neutral }\end{array}$ & $\begin{array}{r}-1.50 \\
-1.36 \\
0.14\end{array}$ & $\begin{array}{l}0.020 \\
0.025 \\
0.719\end{array}$ \\
\hline vigilant/vigilance & $\begin{array}{l}\text { neutral vs. easing } \\
\text { tightening vs. easing* } \\
\text { tightening vs. neutral** }\end{array}$ & $\begin{array}{l}0.00 \\
0.50 \\
0.50\end{array}$ & $\begin{array}{l}1.000 \\
0.062 \\
0.010 \\
\end{array}$ \\
\hline risks to price stability & 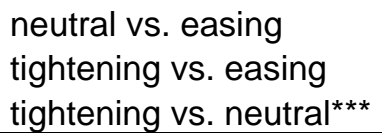 & $\begin{array}{r}-0.50 \\
1.21 \\
1.71\end{array}$ & $\begin{array}{l}0.522 \\
0.107 \\
0.003\end{array}$ \\
\hline $\begin{array}{l}\text { upside risks to price } \\
\text { stability }\end{array}$ & $\begin{array}{l}\text { neutral vs. easing } \\
\text { tightening vs. easing }{ }^{\star \star} \\
\text { tightening vs. neutral }\end{array}$ & $\begin{array}{l}0.25 \\
1.64 \\
1.39 \\
\end{array}$ & $\begin{array}{l}0.741 \\
0.029 \\
0.009\end{array}$ \\
\hline downside risks to growth & neutral vs. easing & -2.00 & 0.000 \\
\hline & $\begin{array}{l}\text { tightening vs. easing } \\
\text { tightening vs. neutral }\end{array}$ & $\begin{array}{r}-2.00 \\
0.00\end{array}$ & $\begin{array}{l}0.000 \\
1.000\end{array}$ \\
\hline $\begin{array}{l}\text { downward pressure on } \\
\text { growth }\end{array}$ & neutral vs. easing ${ }^{\star \star}$ & -0.33 & 0.010 \\
\hline & tightening vs. easing ${ }^{\star \star \star}$ & -0.33 & 0.006 \\
\hline & tightening vs. neutral & 0.00 & 1.000 \\
\hline mixed signals & neutral vs. easing & -0.33 & 0.010 \\
\hline & tightening vs. easing & -0.33 & 0.006 \\
\hline & tightening vs. neutral & 0.00 & 1.000 \\
\hline $\begin{array}{l}\text { favourable outlook for } \\
\text { growth }\end{array}$ & neutral vs. easing & 0.50 & 0.434 \\
\hline & tightening vs. easing ${ }^{\star \star \star}$ & 1.71 & 0.008 \\
\hline & tightening vs. neutral $^{\star \star \star}$ & 1.21 & 0.007 \\
\hline $\begin{array}{l}\text { favourable outlook for } \\
\text { price stability }\end{array}$ & neutral vs. easing & -0.04 & 0.909 \\
\hline & tightening vs. easing & -0.52 & 0.137 \\
\hline & tightening vs. neutral ${ }^{*}$ & -0.48 & 0.054 \\
\hline economic slowdown & neutral vs. easing ${ }^{\star \star \star}$ & -0.88 & 0.002 \\
\hline & tightening vs. easing & -1.00 & 0.000 \\
\hline & tightening vs. neutral & -0.13 & 0.444 \\
\hline
\end{tabular}

$* / * * / * * *$ : significance at $10 \% / 5 \% / 1 \%$

The significant pair-wise tests are used to decide the sign of the specific code word in our indicator. A positive sign is attributed to those words for which tests significantly show larger frequencies in tightening compared to easing periods, tightening compared to neutral periods 
or in neutral compared to easing periods. A negative sign is assigned to words where the significant relative frequencies are opposite. Thus, the resulting indicator is, by construction, positively associated with an increasing "hawkishness" of ECB rhetoric.

Additional information for the learning oriented construction of our wording index comes from the $\eta^{2}$ statistic (measuring the share of the total variance attributable to differences in means between the three different kinds of periods). $\eta^{2}$ is used to provide a weight for the informational contents of different code-words.

Summing up, our wording index WI is constructed using frequency of code words $x_{i}$ as follows:

$$
W I_{t}=\sum_{i=1}^{k} \frac{\operatorname{nobs}\left(x_{i, t}\right)-\operatorname{meanobs}\left(x_{i}\right)}{\operatorname{std} v\left(x_{i}\right)} * \operatorname{sign}\left(x_{i}\right) * \eta^{2}\left(x_{i}\right)
$$

The index adds for each period the (standardized) number of observations. These numbers are weighted by the $\eta^{2}$ in order to account for the differences in the informational content of code words. The sign of each individual code word is determined on the basis of significant pairwise tests in Tables 3 and 4 as described.

We calculate two indicators: First, $\mathrm{WI}_{\mathrm{D}}$ which is based on the information from the complete Duisenberg period January 1999 until October 2003, and, second, $\mathrm{WI}_{9900}$, which only reflects a learning process from the first two years (1999-2000) of the Duisenberg era. The latter indicator is used in the next section for out of sample testing.

Figure 2 presents the two resulting wording indicators together with the minimum bid rate on the main refinancing operations (MRO). While both indicator variants are highly correlated they show differences in behaviour in particular towards the end of the period covered. Since spring 2004, both indicators reveal increasing hawkishness of monetary rhetorics (not being 
followed by monetary action) with the increase being more pronounced for $\mathrm{WI}_{9900}$ compared to $\mathrm{WI}_{\mathrm{D}}$.

Figure 2: Wording Indicators and the Minimum Bid Rate on the MROs

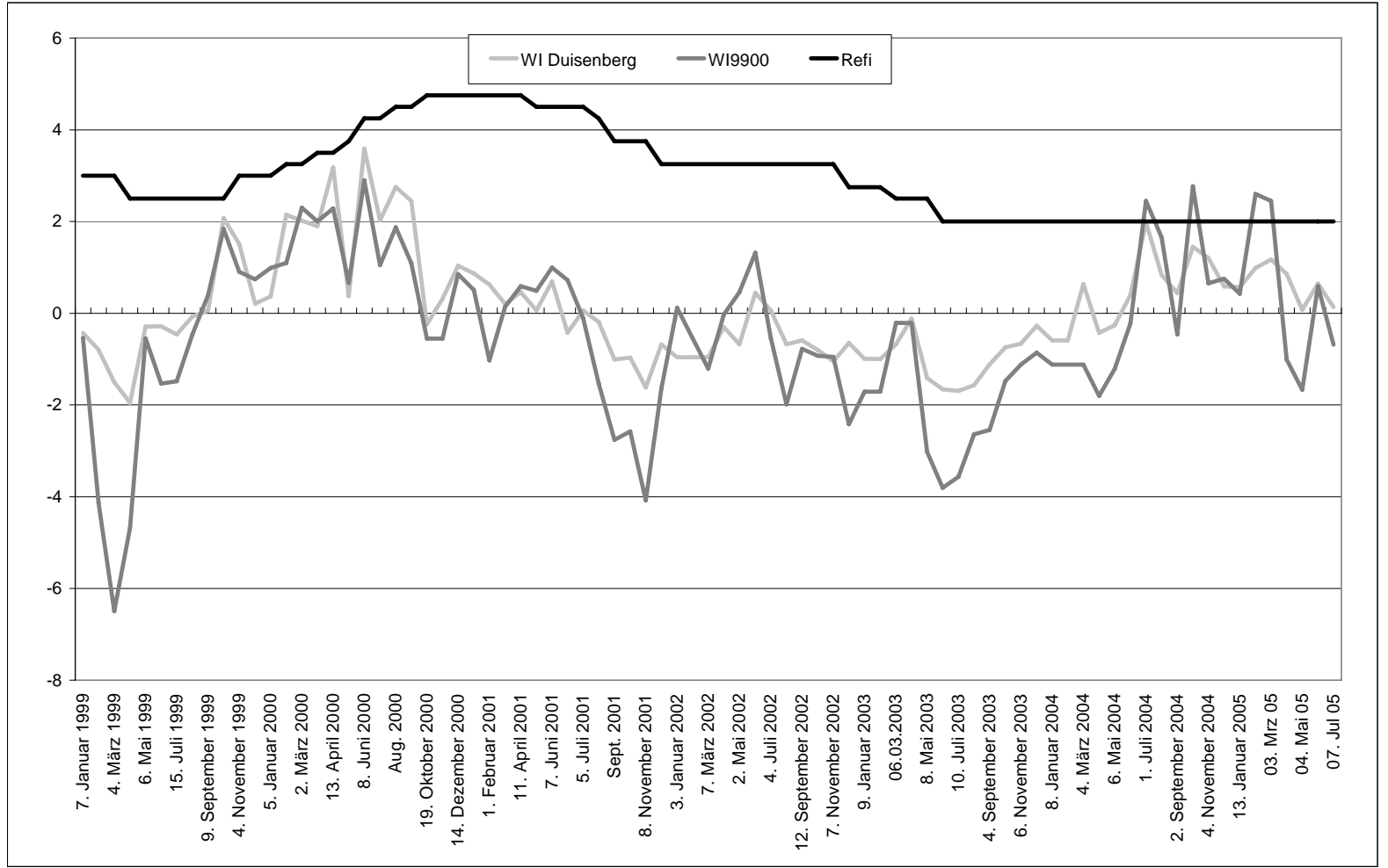

\section{Econometric analysis}

Starting point of our estimation model is a standard ordered probit setup where the Governing Council either increases or decreases the interest rate or leaves it unchanged depending on the divergence between the current target and the interest rate of the last period, $i_{t}^{*}-i_{t-1}$. The ECB Council is modelled to decide on the basis of certain critical thresholds, $\mu_{j}, j=1,2$. If the difference between the target and the actual interest rate last month falls below the lower threshold, we observe an interest rate cut. If the difference is large enough, the interest rate rises. Between the two thresholds an inactive zone is generated: 


$$
\begin{array}{ll}
\Delta i_{t}<0 & \text { if } i_{t}^{*}-i_{t-1} \leq \mu_{1} \\
\Delta i_{t}=0 & \text { if } \mu_{1}<i_{t}^{*}-i_{t-1} \leq \mu_{2} \\
\Delta i_{t}>0 & \text { if } i_{t}^{*}-i_{t-1}>\mu_{2} .
\end{array}
$$

We assume that the target rate is defined on the basis of a smoothing adjustment towards $i_{t}^{F}$ which is the optimal rate of the fully specified model guiding the decision of the Council:

$$
\text { (1) } i_{t}^{*}=\rho i_{t-1}+(1-\rho) i_{t}^{F} \text {. }
$$

A Taylor type interest rate is possibly an incomplete approximation of $i_{t}^{F}$. We model this by regarding the fully specified model as a weighted average of a Taylor target rate $i_{t}^{T}$ and a second target rate, $i_{t}^{O}$, which includes those other aspects in Council preferences which are not taken account of in the Taylor approach and for which central bank watchers hope to get information from wording analyses:

$$
\text { (2) } \quad i_{t}^{F}=\eta i_{t}^{T}+(1-\eta) i_{t}^{O} \text {. }
$$

Thus, $i_{t}^{O}$ is our analytical reference point for which communication and signals become relevant. Only in the extreme case of the Taylor rule explaining the monetary world completely, both target interest rates are identical and the target rate of the fully specified model equals the Taylor interest rate. The intended interest rate $i_{t}^{O}$ can be explained by the intended change of the interest rate, $\Delta i_{t}^{O}$, based on the interest rate of the last period, $i_{t}^{O}=i_{t-1}+\Delta i_{t}^{O}$. Combining this with equations (1) and (2) we get: 


$$
\begin{aligned}
i_{t}^{*} & =\rho i_{t-1}+(1-\rho)\left[\eta i_{t}^{T}+(1-\eta) i_{t}^{O}\right] \\
& =[\rho+(1-\rho)(1-\eta)] i_{t-1}+(1-\rho)\left[\eta i_{t}^{T}+(1-\eta) \Delta i_{t}^{O}\right] .
\end{aligned}
$$

In regard to our econometric specification we now have to specify the Taylor equation. Here, we follow Gerlach (2004) and Rosa and Verga (2005) and use the inflation rate, $\pi$, the output gap, $\bar{y}$, or a related measure, money growth, $\Delta m$, and the annual growth rate of the real effective exchange rate, $\Delta e$, as explanatory variables. Reflecting the availability of monthly data we generally use lagged values:

$$
i_{t}^{T}=\alpha+\beta \pi_{\mathrm{t}-1}+\gamma \bar{y}_{t-1}+\delta \Delta m_{t-1}+\theta \Delta e_{t-1}
$$

Based on these considerations, the central bank would change the interest rate according to equation (5) which is the basis for our regressions:

$$
i_{t}^{*}-i_{t-1}=\Delta^{*} i_{t}=-(1-\rho) \eta i_{t-1}+(1-\rho)\left[\eta\left(\alpha+\beta \pi_{t-1}+\gamma \bar{y}_{t-1}+\delta \Delta m_{t-1}+\theta \Delta e_{t-1}\right)+(1-\eta) \Delta i_{t}^{O}\right]+\varepsilon_{t},
$$

where $\varepsilon$ denotes the error term. In the estimation, we add the lagged change of the interest rate as proposed in Judd and Rudebusch (1998) in order to account for the short run dynamics of the process. Consequently, our estimation model is the following:

$$
\Delta^{*} i_{t}=a_{1} i_{t-1}+a_{2} \Delta i_{t-1}+a_{2} \pi_{t-1}+a_{3} \bar{y}_{t-1}+a_{4} \Delta m_{t-1}+a_{5} \Delta e_{t-1}+a_{6} \Delta i_{t}^{O}+\varepsilon_{t}
$$

where $\Delta i$ denotes the change in the interest rate on the MRO.

The following data are used: Our interest rate $i$ denotes the interest rate on the main refinancing operations (MRO) (Source: ECB). The yearly inflation rate $\pi$ is based on the 
harmonized index of consumer prices HICP (Source: Eurostat). The output gap $\bar{y}$ is calculated as the difference in per cent between the seasonally adjusted index of industrial production including construction (Source: Eurostat) and the HP filtered series. Alternatively, the seasonally adjusted series of the economic sentiment indicator, published by the European Commission, is used in the form $((\text { esi- } \overline{e s i}) / \overline{\text { esi }})^{*} 100$, where $\overline{\text { esi }}$ is the mean of the series (Galí et al. 2004). With $\Delta m$ we denote the seasonally adjusted annual growth rate of the monetary aggregate M3 (Source: ECB) averaged over the last three months. The yearly growth rate of the exchange rate is based on the real CPI effective exchange rate index (EER42, Source: ECB).

We employ our wording indicator lagged one month $w_{t-1}$ as a proxy for $\Delta i_{t}^{O}$. Thus, the explanatory value of this indicator is to reveal the extent to which rhetoric signals contain information about the monetary decision process which is not included in the standard Taylor approach variables.

Using the wording indicator we face the problem that not every month has seen an ECB press conference and sometimes there were two of these events in one month. We treat the missing value problem by evaluating the editorial of the Monthly Bulletin instead. The double values are replaced by their respective average.

Table 5 shows descriptive statistics of the explanatory variables. The maximum interest rate steps are \pm 0.5 percentage points. The economic sentiment indicator esi displays the highest variance closely followed by the exchange rate variable. 
Table 5: The used time series span from 1999:1 to 2005:5 has 74 observations in each series.

\begin{tabular}{llllllllll}
\hline & $\mathrm{i}$ & $\Delta i$ & $\pi$ & $\bar{y}$ & $\mathrm{esi}$ & $\Delta m$ & $\Delta e$ & $\mathrm{Wl}_{\mathrm{D}}$ & $\mathrm{Wl} \mathrm{l}_{9900}$ \\
\hline Mean & 3.03 & 0.99 & 2.02 & 0.01 & 0.13 & 6.22 & 1.23 & 0.08 & -0.47 \\
Median & 3.00 & 1.00 & 2.10 & -0.14 & -1.07 & 5.93 & 2.00 & -0.15 & -0.50 \\
Maximum & 4.75 & 2.00 & 3.10 & 2.67 & 14.74 & 8.70 & 15.99 & 3.59 & 2.90 \\
Minimum & 2.00 & 0.00 & 0.80 & -2.62 & -12.83 & 3.80 & -13.95 & -1.95 & -4.97 \\
Std. Dev. & 0.94 & 0.45 & 0.46 & 1.14 & 7.74 & 1.32 & 7.72 & 1.20 & 1.81 \\
\hline
\end{tabular}

As standard in Taylor regressions we expect the following signs: a higher inflation rate should lead to a higher probability of an interest rate increase. The same holds for the output gap, the economic sentiment and money growth. The lagged change of the interest rate is to reveal smoothing behaviour. A positive growth rate of the exchange rate means an appreciation of the Euro vis-à-vis the rest of the world. This would reduce the risk of inflation and the probability of an interest rate cut would rise. Last but not least, the wording indicator should show a positive sign since a high indicator value signals a large extent of "hawkishness" leading to a higher probability of an interest rate increase.

According to our testing strategy described in section 2 we estimate basically three variants of a model explaining ECB interest rate changes. Our baseline model is a standard Taylor approach. We contrast this first to both a "naïve" central bank watcher model where no information is used but wording and the interest rate's history and second to a Taylor equation augmented by the wording index.

We apply this testing strategy to two periods with the different wording indicators described above in order to supply both within and out of sample insights. The first set of regressions (Table 6) represents a within sample approach: The Duisenberg era wording indicator $\left(\mathrm{WI}_{\mathrm{D}}\right)$ is used to explain interest rate decisions which have been used to construct this indicator. The second set of regressions (Table 7) is an out of sample exercise: The wording indicator 
employed $\left(\mathrm{WI}_{9900}\right)$ was constructed on the basis of information from periods (1999-2000) not included in the estimation period (2001:01 - 2005:03). It thus can be interpreted to represent the following sequence of learning: The first two years of the newly established central bank are used by ECB watchers to learn about the meaning of code words. Subsequently, this new knowledge is available to improve predictability of interest rate decisions. Although being the superior approach judging on methodological considerations, the second set of regressions suffers from a loss of observations excluding all cases of increasing interest rates from the analysis.

Our baseline regressions are presented in columns (1) and (4) where $\mu_{1}$ and $\mu_{2}$ denote the estimated thresholds separating the categories (in estimation equation (4) only one threshold exists since the covered period does not include any increases in interest rates). Estimations using the output gap as an alternative to the economic sentiment indicator are contained in the appendix (table B). For the full sample (1), all explanatory variables included in the Taylor approach are significant, at least at the 10 percent level. For the second time period, this specification does not give reasonable results. Therefore, we rely on the basic Taylor specification including only the lagged interest rate, change of the interest rate, inflation rate and economic sentiment indicator. In this restricted regression (4), apart from the lagged interest rate only the economic sentiment indicator appears to be significant. 
Table 6: Coefficients of the ordered probit estimation (z-statistic in brackets)
(1)
(2)
(3)

Adjusted sample

1999:3 - 2005:4

\begin{tabular}{|c|c|c|c|}
\hline$i_{t-1}$ & $-1.31^{\text {** }}$ & $-0.34^{*}$ & $-1.60^{* * *}$ \\
\hline $1 \mathrm{t}-1$ & $(-2.26)$ & $(-1.70)$ & $(-2.05)$ \\
\hline \multirow{2}{*}{$\Delta i_{t-1}$} & $-2.96^{*}$ & & $-4.22^{* *}$ \\
\hline & $(-1.78)$ & & $(-2.19)$ \\
\hline \multirow{2}{*}{$\pi_{t-1}$} & $1.65^{* *}$ & & 1.20 \\
\hline & $(2.03)$ & & $(1.32)$ \\
\hline \multirow{2}{*}{$e s i_{t-1}$} & $0.26^{* * *}$ & & $0.19^{*}$ \\
\hline & $(2.59)$ & & (1.74) \\
\hline \multirow{2}{*}{$\Delta m_{t-1}$} & $1.13^{* * *}$ & & $1.01^{* * *}$ \\
\hline & $(2.65)$ & & $(2.48)$ \\
\hline \multirow[b]{2}{*}{$\Delta e_{t-1}$} & $-0.21^{* * * *}$ & & $-0.24^{* * *}$ \\
\hline & $(-2.70)$ & & $(-2.59)$ \\
\hline \multirow[b]{2}{*}{$W I_{D, t-1}$} & & $0.72^{* * *}$ & $0.81^{\text {** }}$ \\
\hline & & $(3.85)$ & $(2.06)$ \\
\hline \multirow{3}{*}{$\mu_{1}$} & 3.42 & $-2.57^{\text {**** }}$ & 0.45 \\
\hline & $(0.99)$ & $(3.52)$ & $(0.11)$ \\
\hline & $9.24^{* * *}$ & 0.78 & $7.50^{* * *}$ \\
\hline$\mu_{2}$ & $(2.45)$ & $(1.32)$ & $(2.00)$ \\
\hline Log likelihood & -22.81 & -37.54 & -20.21 \\
\hline $\begin{array}{l}\text { Restr. log } \\
\text { likelihood }\end{array}$ & & -47.67 & \\
\hline Pseudo $\mathrm{R}^{2}$ & 0.5215 & 0.2125 & 0.5761 \\
\hline
\end{tabular}

Significance at the $1\left(^{* * *}\right), 5(* *), 10(*)$ per cent level 
Table 7: Coefficients of the ordered probit estimation (z-statistic in brackets)

(4)

(5)
(6)

Adjusted sample

2001:1-2005:4

\begin{tabular}{|c|c|c|c|}
\hline$i_{t-1}$ & $\begin{array}{l}-1.82^{* *} \\
(-1.99)\end{array}$ & $\begin{array}{l}-0.77^{* *} \\
(-234)\end{array}$ & $\begin{array}{l}-3.36^{* *} \\
(-210)\end{array}$ \\
\hline$\Delta i_{t-1}$ & $\begin{array}{c}(-1.99) \\
-3.27 \\
(-1.33)\end{array}$ & & $\begin{array}{c}-13.21 \\
(-1.98)\end{array}$ \\
\hline$\pi_{t-1}$ & $\begin{array}{l}-0.27 \\
(-0.24)\end{array}$ & & $\begin{array}{l}-5.04 \\
(-1.64)\end{array}$ \\
\hline$e s i_{t-1}$ & $\begin{array}{l}0.22^{* *} \\
(2.10)\end{array}$ & & $\begin{array}{c}0.20 \\
(1.54)\end{array}$ \\
\hline$W I_{9900, t-1}$ & & $\begin{array}{c}0.39^{*} \\
(1.78)\end{array}$ & $\begin{array}{l}2.28^{*} \\
(1.82)\end{array}$ \\
\hline$\mu$ & $\begin{array}{l}-8.67^{* *} \\
(-2.28) \\
\end{array}$ & $\begin{array}{l}-4.00^{* * *} \\
(-3.02)\end{array}$ & $\begin{array}{l}-27.11^{* *} \\
(-2.09)\end{array}$ \\
\hline Log likelihood & -13.28 & -16.04 & -9.66 \\
\hline $\begin{array}{l}\text { Restr. log } \\
\text { likelyhood }\end{array}$ & & -20.54 & \\
\hline Pseudo $\mathrm{R}^{2}$ & 0.3535 & 0.2193 & 0.5297 \\
\hline
\end{tabular}

Significance at the $1(* * *), 5(* *), 10(*)$ per cent level

The naïve regressions (2) and (5) based solely on the wording indicator and past values of the interest rates show a poorer fit compared to the Taylor specification (1) and (4). Even though the wording indicator is significant in both approaches, it cannot fully substitute the more thorough economic modelling.

Regressions (3) and (6) test for the informative added value of ECB rhetoric by augmenting the Taylor specification by our wording indicators. This indicator turns out to be significant in the within sample regression as well as in the out of sample regression at the 5 or 10 per cent level. The regressions' fits increase with the inclusion of the wording indicators; the improvement is particularly marked for the out of sample analysis (as can be seen from a comparison of (6) with (4)). But for the within sample estimation, the wording indicator seems to replace the inflation rate. As the ECB stresses that its foremost objective is achieving price level stability, this estimation result could hint for the reflection of the objective in the rhetoric. Because the ECB cares so much about inflation, its wording can replace the inflation 
rate in the estimation. For the out of sample analysis, both basis variables, the inflation rate and the economic sentiment are not significant anymore. Nevertheless, their inclusion improves the value of the log likelihood considerably as the comparison between estimation (5) and (6) shows.

To assess the influence of the variables on the probability of an interest rate decrease, increase or of an unchanged interest rate, the marginal effects of the variables are evaluated at their mean and displayed in Table 8. For some of the variables the sum of the probabilities does not add to zero because of truncation effects.

If the mean of the wording indicator increases by one point, this would lead to a decrease in the probability of an interest rate cut by 0.002 and to an increase in the probability of an unchanged interest rate or increasing interest rate by 0.001 or 0.0002 , respectively, for model (3). Thus, the size of the marginal effect of the wording indicator is comparable to that of the inflation rate, money growth or the lagged interest rate. The influence growth rate of the exchange rate is even lower. The high degree of interest rate smoothing reported in other studies (e.g. Fourçans and Vranceanu 2004) is apparent in these equations, too. The lagged change of the target interest rate has the largest effect on the probabilities. A large interest rate step last month is not followed by an even larger step but rather by an unchanged or falling rate, the probability of an interest rate cut rises. 
Table 8: Marginal effects of change in mean of the explanatory variable

\begin{tabular}{|c|c|c|c|c|c|c|c|c|c|}
\hline & \multicolumn{3}{|c|}{$\begin{array}{l}\text { interest rate decrease } \\
\operatorname{Prob}(\mathrm{y}=0)\end{array}$} & \multicolumn{3}{|c|}{$\begin{array}{l}\text { unchanged interest rate } \\
\operatorname{Prob}(\mathrm{y}=1)\end{array}$} & \multicolumn{3}{|c|}{$\begin{array}{l}\text { interest rate increase } \\
\operatorname{Prob}(\mathrm{y}=2)\end{array}$} \\
\hline & (1) & (2) & (3) & (1) & (2) & (3) & (1) & (2) & (3) \\
\hline $\bar{i}$ & 0.012 & 0.037 & 0.003 & -0.007 & -0.007 & -0.003 & -0.005 & -0.030 & -0.000 \\
\hline$\Delta i$ & 0.027 & & 0.008 & -0.016 & & -0.008 & -0.011 & & -0.001 \\
\hline$\pi$ & -0.015 & & -0.002 & 0.009 & & 0.002 & 0.006 & & 0.000 \\
\hline esi & -0.002 & & -0.000 & 0.001 & & 0.000 & 0.001 & & 0.000 \\
\hline$\Delta m$ & -0.010 & & -0.002 & 0.006 & & 0.002 & 0.004 & & 0.000 \\
\hline$\Delta e$ & 0.002 & & 0.001 & -0.001 & & -0.000 & -0.001 & & 0.000 \\
\hline$w$ & & $-0,078$ & -0.002 & & 0.015 & 0.001 & & 0.063 & 0.000 \\
\hline
\end{tabular}

To evaluate whether the prediction of interest rate changes differs from the basic equation if the wording indicator is included, refer to Table 9, which displays the prediction of policy rate changes for the different models. By including the wording indicator into the Taylor equation, the error predicting interest changes decreases by forecasting fewer points with unchanged interest rates in favour of the two other categories. Especially the forecast of interest rate increases improves. Again the poor performance of the naïve approach (2) becomes apparent with virtually no discriminatory power between different monetary phases.

Table 9: Prediction of interest rate changes.

\begin{tabular}{|l|c|c|c|c|c|c|c|}
\hline & Count & \multicolumn{2}{|c|}{ Counts of observations with } & \multicolumn{3}{|c|}{ Error } \\
& & \multicolumn{3}{c}{ maximum probability } & & \\
& & $(1)$ & $(2)$ & $(3)$ & $(1)$ & $(2)$ & $(3)$ \\
\hline$\Delta i<0$ & 8 & 2 & 0 & 4 & 6 & 8 & 4 \\
\hline$\Delta i=0$ & 59 & 68 & 74 & 64 & -9 & -15 & -5 \\
\hline$\Delta i>0$ & 7 & 4 & 0 & 6 & 3 & 7 & 1 \\
\hline
\end{tabular}




\section{Conclusions}

In this paper's title we pose the question „does it pay to watch central bankers' lips”? Judging on the experience with the ECB we answer this question in the affirmative. Compared to technical approaches based on standard Taylor equations and solely hard economic data the exploitation of rhetoric signals can be helpful to better explain what the central bank is doing. This result is confirmed on the basis of out of sample analysis where the period on which the wording indicator's choice of weights is based is not included in testing this indicator's significance. Thus, we tend to accept the hypothesis that wording includes information helpful to improve the explanation of interest rate decisions based on standard explanatory models. This also indicates that Taylor regressions are not able to capture the realities of monetary policy completely - a fact which seems sometimes to be ignored in the literature.

It should be stressed that our wording indicator based on statistical reasoning is nevertheless rather mechanical and only an approximation for the information content of wording. It cannot capture the art of reading between the lines of central bankers' statements. In this sense our results for the informative contents of wording must be regarded to be of a conservative nature.

Although our analysis hints to the usefulness of rhetoric signals it also indicates its limitation. Market participants benefiting from a correct prediction of monetary decisions are well advised to employ also more rigorous models for their forecasts in addition to listening to ECB press conferences. Our findings largely indicate that judgements based solely on analysing central bankers' speeches are inferior to more refined approaches based on models and economic data. 


\section{References}

Andersson, Malin, Hans Dillén and Peter Sellin (2001), Monetary Policy Signaling and Movements in the Swedish Term Structure of Interest Rates, Sveriges Riksbank Working Paper No. 132.

Breuss, Fritz (2002), Was ECB's Monetary Policy Optimal, Atlantic Economic Journal 30 (3): 298-320.

Clarida, Richard, Jordi Galí and Mark Gertler (1998), Monetary Policy Rules in Practice: Some International Evidence, European Economic Review 42: 1033-1067.

Conley, Timothy, Bill Dupor and Tokhir Mirzoev (2004), Does the Federal Reserve Do What It Says It Expects to Do?, Working Paper.

Faust, Jon and Eric T. Swanson and Jonathan H. Wright (2004), Do Federal Reserve Policy Surprises Reveal Superior Information about the Economy?, Contributions to Macroeconomics, 4 (1).

Fourçans, André and Radu Vranceanu (2004), The ECB Interest Rate Rule under the Duisenberg Presidency, European Journal of Political Economy, 20 (3): 579-595.

Fratzscher, Marcel (2004), Communication and Exchange Rate Policy, ECB Working Paper, No. 363, May 2004.

Galí, Jordi and Stefan Gerlach and Julio Rotemberg and Harald Uhlig and Michael Woodford (2004), The Monetary Policy Strategy of the ECB Reconsidered. Monitoring the European Central Bank 5, CEPR, London.

Gaspar, Vítor, Gabriel Pérez Quiros and Jorge Sicilia (2001), The ECB Monetary Policy Strategy and the Money Market, ECB Working Paper No. 69.

Gerlach, Stefan (2004), Interest Rate Setting by the ECB: Words and Deeds, CEPR Discussion Paper No. 4775.

Gerlach-Kristen, Petra (2004), Is the MPC's Voting Record Informative about Future UK Monetary Policy?, Scandinavian Journal of Economics, 106 (2): 299-313.

Görgens, Egon and Karlheinz Ruckriegel and Frank Seitz (2001), Europäische Geldpolitik. Theorie, Empirie, Praxis, Werner, Düsseldorf.

Guthrie, Graeme and Julian Wright (2000), Open Mouth Operations, Journal of Monetary Economics, 46: 489-516.

Heinemann, Friedrich and Felix Hüfner (2004), Is the View from the Eurotower Purely European? National Divergence and ECB Interest Rate Policy, in: Scottish Journal of Political Economy, 51 (4), S. 544-557.

Jansen, David-Jan and Jakob de Haan (2004), Look Who's Talking: ECB Communications During the First Years of EMU, CESifo Working Paper No. 1263.

Mayer, Thomas (2004), The Risks to Price Stability, Deutsche Bank, Global Markets Research, Focus Europe, 19 July 2004, p. 7-9.

Rosa, Carlo and Giovanni Verga (2005), The Importance of Wording of the ECB, Centre for Economic Performance Discussion Paper No. 694. 
Ross, Kevin (2002), Market Predictability of ECB Monetary Policy Decisions: A Comparative Examination, IMF Working Paper No. 233.

Sarno, Lucio, Daniel L. Thornton and Giorgio Valente (2004), Federal Funds Rate Prediction, CEPR Discussion Paper No. 4587.

Taylor, John B. (1993), Discretion versus Policy Rules in Practice, Carnegie-Rochester Conference Series on Public Policy, 39: 195-214.

Without author (2003), Glossar der geldpolitischen Signalsprache der EZB, Börsenzeitung, Nr. 152, 9 August 2003, p. 7. 


\section{Appendix}

Table A: Potential code words with examples of use

\begin{tabular}{|c|c|}
\hline Code word & Examples \\
\hline "appropriate" & $\begin{array}{l}\text { The Governing Council concluded that the information } \\
\text { which had become available in recent weeks confirmed that } \\
\text { the current level of key ECB interest rates remains } \\
\text { appropriate for the maintenance of price stability over the } \\
\text { medium term ( } 7 \text { March 2002). } \\
\text { Overall, the current monetary policy stance remains } \\
\text { appropriate to preserve a favourable outlook for price } \\
\text { stability in the medium term ( } 6 \text { February 2003). } \\
\text { We judge the current monetary policy stance appropriate to } \\
\text { maintain a favourable outlook for price stability in the } \\
\text { medium term. Hence, we have decided to keep our key rates } \\
\text { unchanged (9 January 2003). }\end{array}$ \\
\hline "in line with price stability" & $\begin{array}{l}\text { On the basis of our regular economic and monetary analysis, } \\
\text { we have not changed our assessment that the current stance } \\
\text { of monetary policy remains in line with the maintenance of } \\
\text { price stability over the medium term ( } 1 \text { April 2004). } \\
\text { In summary, the economic analysis indicates that the main } \\
\text { scenario for price developments in the medium term } \\
\text { continues to be in line with our definition of price stability } \\
\text { (4 December 2003). }\end{array}$ \\
\hline "for the time being" & $\begin{array}{l}\text { To sum up, the economic analysis continues to indicate that } \\
\text { the main scenario for price developments in the coming } \\
\text { years is in line with price stability. Cross-checking with the } \\
\text { monetary analysis does not alter this picture for the time } \\
\text { being ( } 4 \text { March 2004). } \\
\text { For the time being, we thus see a confirmation of our } \\
\text { earlier assessment, which led us to reduce the key ECB } \\
\text { interest rates by } 50 \text { basis points on } 17 \text { September. In fact, } \\
\text { the recent events strengthened tendencies towards lower } \\
\text { rates of inflation that were already prevailing before (11 } \\
\text { October 2001). }\end{array}$ \\
\hline "observe" & $\begin{array}{l}\text { Over the coming months, volatility in annual inflation rates } \\
\text { is likely to be observed, mainly due to further base effects } \\
\text { from energy prices as well as to increases in indirect taxes ( } 4 \\
\text { March 2004). } \\
\text { As I have already noted on previous occasions, the rise in } \\
\text { the Harmonised Index of Consumer Prices (HICP) which we }\end{array}$ \\
\hline
\end{tabular}




\begin{tabular}{|c|c|}
\hline & $\begin{array}{l}\text { have observed over recent months stems, to a large extent, } \\
\text { from the combined effects of both oil price and exchange } \\
\text { rate developments ( } 13 \text { April 2000). }\end{array}$ \\
\hline "monitor" & $\begin{array}{l}\text { The Governing Council will carefully monitor future } \\
\text { developments and assess whether conditions for price } \\
\text { stability continue to develop favourably ( } 8 \text { May 2003). } \\
\text { In view of the high uncertainty on future growth, and its } \\
\text { implication for medium-term inflationary developments, the } \\
\text { Governing Council has discussed extensively the arguments } \\
\text { for and against a cut in the key ECB interest rates. The view } \\
\text { has prevailed to keep interest rates unchanged. However, the } \\
\text { Governing Council will monitor closely the downside risks } \\
\text { to economic growth in the euro area ( } 7 \text { November 2002). }\end{array}$ \\
\hline & $\begin{array}{l}\text { As always, we will continue to monitor carefully all } \\
\text { developments that could affect our assessment of risks to } \\
\text { price stability over the medium term ( } 6 \text { May 2004). }\end{array}$ \\
\hline "vigilant"/"vigila1 & $\begin{array}{l}\text { The Eurosystem will remain vigilant in assessing upside } \\
\text { risks to price stability and will take appropriate action if and } \\
\text { when required ( } 13 \text { April 2000). } \\
\text { The Governing Council will remain vigilant with regard to } \\
\text { all developments which could affect the risks to price } \\
\text { stability over the medium term ( } 1 \text { July 2004). }\end{array}$ \\
\hline "risks to price stability" & $\begin{array}{l}\text { We will remain vigilant with regard to all developments } \\
\text { which could affect the risks to price stability over the } \\
\text { medium term ( } 4 \text { June } 2004 \text { ). } \\
\text { As always, we will continue to monitor carefully all } \\
\text { developments that could affect our assessment of risks to } \\
\text { price stability over the medium term (6 May 2004). }\end{array}$ \\
\hline $\begin{array}{l}\text { "upside/upward risks to price } \\
\text { stability" }\end{array}$ & $\begin{array}{l}\text { To sum up, annual inflation rates should fall below } 2 \% \text { in } \\
2005 \text {, but a number of medium-term upside risks to price } \\
\text { stability need to be carefully monitored ( } 7 \text { October } 2004 \text { ). }\end{array}$ \\
\hline $\begin{array}{l}\text { "upside/upward pressure on } \\
\text { inflation" }\end{array}$ & $\begin{array}{l}\text { Over the short term, oil prices continue to exert upward } \\
\text { pressure on the general price level ( } 1 \text { July 2004). } \\
\text { Due to the increase in oil prices, some renewed upward } \\
\text { pressure on consumer prices is likely to have emerged } \\
\text { around the turn of the year ( } 9 \text { January } 2003) \text {. } \\
\text { I noted earlier that, from a monetary policy point of view, } \\
\text { these developments are a cause for concern as they add to } \\
\text { the upward pressure on consumer prices in the euro area } \\
\text { (14 September 2000). }\end{array}$ \\
\hline $\begin{array}{l}\text { "downside/downward risks to } \\
\text { growth/economic activity" }\end{array}$ & $\begin{array}{l}\text { Overall, with regard to the cyclical situation, recent data } \\
\text { confirm our earlier expectations that there are still downside }\end{array}$ \\
\hline
\end{tabular}




\begin{tabular}{|c|c|}
\hline & $\begin{array}{l}\text { risks for output growth ( } 4 \text { March 1999). } \\
\text { Sources of downside risks - including oil prices, } \\
\text { imbalances in the global economy, financial market } \\
\text { uncertainties and their impact on consumption, investment, } \\
\text { and thus on employment - will be monitored closely (10 } \\
\text { October 2002). }\end{array}$ \\
\hline "second round effects" & $\begin{array}{l}\text { These risks relate mainly to oil price developments and their } \\
\text { potential to lead to second-round effects stemming from } \\
\text { wage and price-setting behaviour ( } 7 \text { July 2005). } \\
\text { Inflation rates are now approaching higher levels than } \\
\text { expected earlier, and larger and more protracted commodity } \\
\text { and producer price increases are heightening the risk of } \\
\text { second round effects ( } 3 \text { February } 2000) \text {. }\end{array}$ \\
\hline "appropriate action" & $\begin{array}{l}\text { The Eurosystem will remain vigilant in assessing upside } \\
\text { risks to price stability and will take appropriate action if } \\
\text { and when required ( } 13 \text { April 2000). }\end{array}$ \\
\hline "alert" & $\begin{array}{l}\text { The Governing Council will continue to remain alert to } \\
\text { emerging risks to price stability ( } 14 \text { September } 2000 \text { ). }\end{array}$ \\
\hline "mixed signals" & $\begin{array}{l}\text { Recent data and survey indicators on economic activity have } \\
\text { been mixed. In general they point to ongoing economic } \\
\text { growth at a moderate pace over the short term, with no clear } \\
\text { signs as yet of a strengthening in underlying dynamics ( } 7 \\
\text { April 2005). } \\
\text { Our conclusion was that while risks to price stability over } \\
\text { the medium term remain tilted to the upside, recent evidence } \\
\text { sends mixed signals (4 July 2002). }\end{array}$ \\
\hline $\begin{array}{l}\text { "favourable outlook for } \\
\text { growth" }\end{array}$ & $\begin{array}{l}\text { Reflecting favourable domestic and external conditions for } \\
\text { growth, the outlook for euro area growth continues to be } \\
\text { positive (6 July 2000). } \\
\text { The more favourable expectations for economic } \\
\text { development in the euro area are partly connected with a } \\
\text { further improved outlook for the world economy ( } 7 \text { October } \\
\text { 1999). }\end{array}$ \\
\hline $\begin{array}{l}\text { "favourable outlook for price } \\
\text { stability" }\end{array}$ & $\begin{array}{l}\text { Overall, the Governing Council confirmed its previous } \\
\text { assessment of a favourable outlook for price stability in } \\
\text { the euro area over the medium term ( } 4 \text { March } 2004) \text {. } \\
\text { We judge the current monetary policy stance appropriate to } \\
\text { maintain a favourable outlook for price stability in the } \\
\text { medium term (9 January 2003). }\end{array}$ \\
\hline $\begin{array}{l}\text { "compatible/consistent with } \\
\text { price stability" }\end{array}$ & $\begin{array}{l}\text { Overall, as several indicators are pointing to an abatement of } \\
\text { inflationary pressures, the new level of interest rates is } \\
\text { compatible with the maintenance of price stability over } \\
\text { the medium term ( } 30 \text { August 2001). } \\
\text { Markets still expect an evolution of consumer prices, which }\end{array}$ \\
\hline
\end{tabular}




\begin{tabular}{|l|l|}
\hline "balanced" & $\begin{array}{l}\text { will remain compatible with price stability (9 September } \\
\text { 1999). }\end{array}$ \\
\hline $\begin{array}{l}\text { Our conclusion is that risks to price stability are at present } \\
\text { balanced (10 October 2002). } \\
\text { The decision to keep interest rates unchanged reflects the } \\
\text { Governing Council's assessment that the risks to price } \\
\text { stability in the medium term now appear more balanced } \\
\text { than at the end of last year (1 February 2001). }\end{array}$ \\
\hline "economic slowdown" & $\begin{array}{l}\text { First, when looking back, we recognise that inflation has } \\
\text { been rather persistent despite the economic slowdown (5 } \\
\text { December 2002). } \\
\text { First, the slowdown in economic activity which I just } \\
\text { mentioned may contribute to containing inflationary } \\
\text { pressure stemming from the labour market (30 August } \\
2001) .\end{array}$ \\
\hline number of words & \multicolumn{2}{|l}{} \\
\hline
\end{tabular}

Table B: Estimations using the output gap

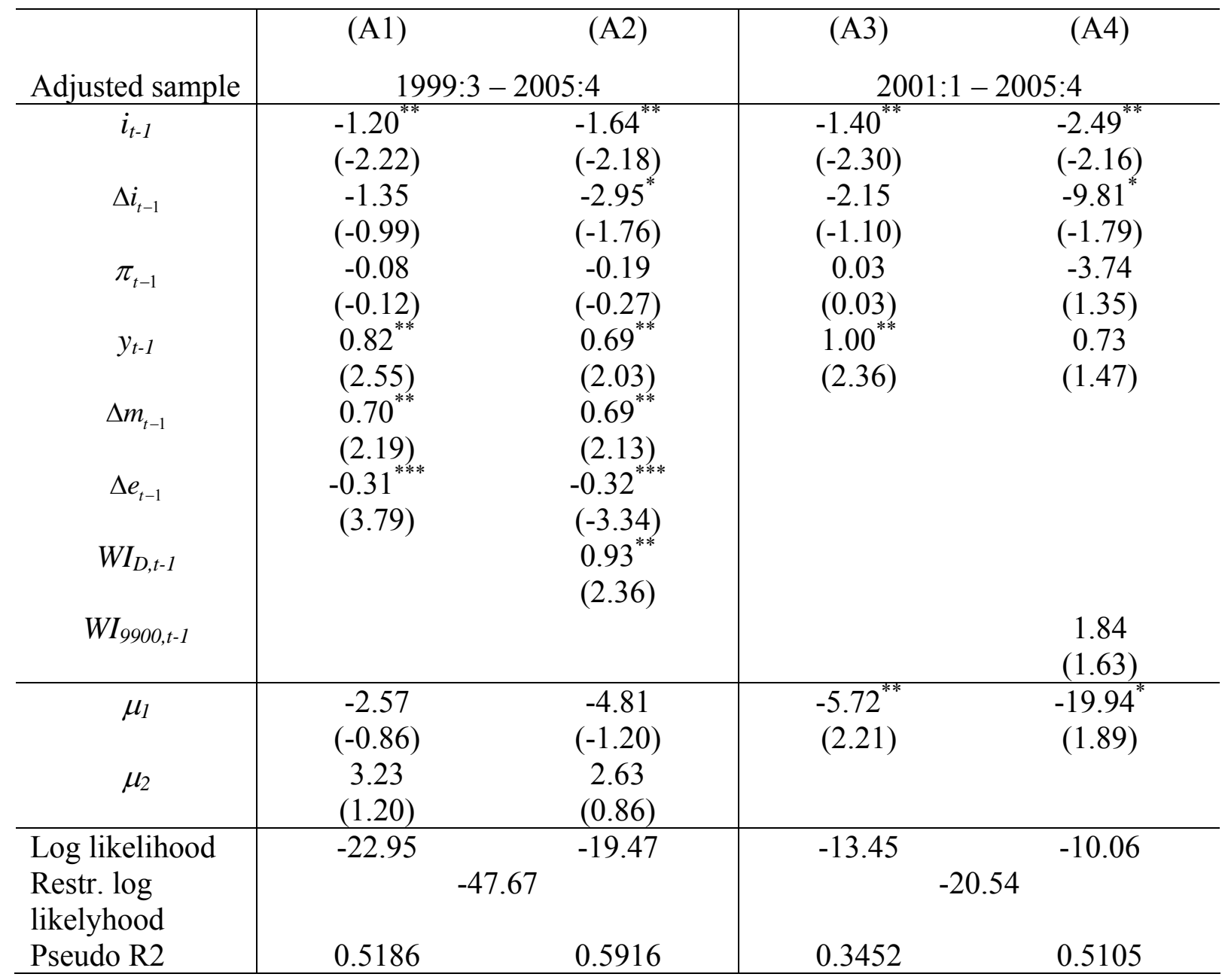

